\title{
Regional Register of Cesarean Sections "C-Register"
}

\author{
Ankudinov NO ${ }^{1 *}$, Zilber $\mathrm{NA}^{2}$, Ankudinov $\mathrm{NO}^{3}$ and Sitnikov $\mathrm{AF}^{4}$ \\ ${ }^{1}$ Regional Obstetric Center of the Sverdlovsk region Regional Children Clinical Hospital Ekaterinburg, Russia \\ ${ }^{2}$ Head of the Department for Organization of Aid to Mothers and Children of the Ministry of Health of the Sverdlovsk Region, Russia \\ ${ }^{3}$ Obstetrician-gynecologist, head of the admission department of the regional perinatal center GAUZ SO "CSTO", Russia \\ ${ }^{4}$ Deputy Chief Physician for the medical department of PET-Technology LLC, Yekaterinburg Nuclear Medicine Center, Russia
}

*Corresponding author: Ankudinov NO, Head of the admission department of the regional perinatal center, Regional Obstetric Center of the Sverdlovsk region Regional Children Clinical Hospital Ekaterinburg, Russia, Yekaterinburg, Russia.

Received Date: November 02, 2020

Published Date: November 23, 2020

\section{Summary}

The role of information technology in obstetrics

- Continuous monitoring of all caesarean section operations both in the context of medical organizations and the entire region.

- "Digitization" of all medical documentation on operative delivery from preoperative epicrisis to risk assessment of VTEC after cesarean section

- Automation of Robson classification

Keywords: Information technology, health care, obstetrics, Robson classification, medical decision support systems, analytics of the activities of medical organizations, caesarean sections, risk assessment of VTEC, electronic protocol of operations

Abstract

Information technology in obstetrics

- Continuous monitoring of all cesarean section operations in the context of medical organizations and the entire region.

- Digitization of all medical documentation on operative delivery from preoperative epicrisis to risk assessment of VTE0 after cesarean section

- Automation of the classification of Robson

Keys

Information technology, healthcare, obstetrics, classification of MS Robson, medical decision support systems, analytics of medical organizations, cesarean sections, risk assessment of VTE, electronic protocol of operations.

Caesarean section is one of the most common surgical procedures in the world, and its frequency continues to increase, especially in high- and middle-income countries. While caesarean sections can save lives, they are often performed without a medical indication, putting women and their children at risk of developing health problems in the short or long term. A caesarean section may be necessary when a vaginal delivery can be dangerous for the mother or baby. At the same time, a caesarean section can lead to serious complications, disability or death, especially in the 
absence of the ability to safely perform surgery or treat possible complications.

In order to improve the quality of medical care for pregnant women and improve systems to support medical decision-making in operational obstetrics, automate the analytics of the activities of obstetric care institutions, including Robson's classification, it was decided to develop and introduce the regional register of cesarean sections "KesRegister" in the Sverdlovsk region as a structural -functional module of the automated information system "Regional Obstetric Monitoring" (hereinafter - AIST "RAM").

The register automatically "collects" information on all operations of cesarean section and manipulations performed intraoperatively, in digital form in the entire region.

Thanks to the work in the AIST "RAM" region, it was possible to collect information on cases of delivery by caesarean section from electronic medical records for the period preceding the introduction of the register, and thus got the opportunity for automated analytics and implementation of SPPVR in terms of operational obstetrics.

A multifunctional filter has been created for the selection of certain cases online, taking into account the level of MR, the volume of blood loss, the timing of delivery and intraoperative manipulations.

The classification of Robson's caesarean section operations is now generated automatically, thereby minimizing the influence of the human factor and the possibility of distorting real results.

The classification of caesarean section operations is recommended for use by WHO and the Letter of the Ministry of Health of the Russian Federation dated February 19, 2019 No. 15-4/I/2-1286. This report can be obtained for any period for any medical organization or region as a whole. The report can be obtained both in tabular and graphical form.

On the basis of KesRegistr, a system of mobile notifications was created and configured for online quality control of medical care and quick adoption of organizational and administrative decisions.

The leaders of the MO can receive the following information within the framework of their MO on the phone online:

- About all caesarean section operations taking into account the volume of blood loss, intraoperative manipulations and the condition of the newborn;

- Healthcare providers can receive the following information by phone online:

- $\quad$ About all operations of caesarean section in the 1st level MO

- About all pathological blood loss during cesarean section

\section{Results}

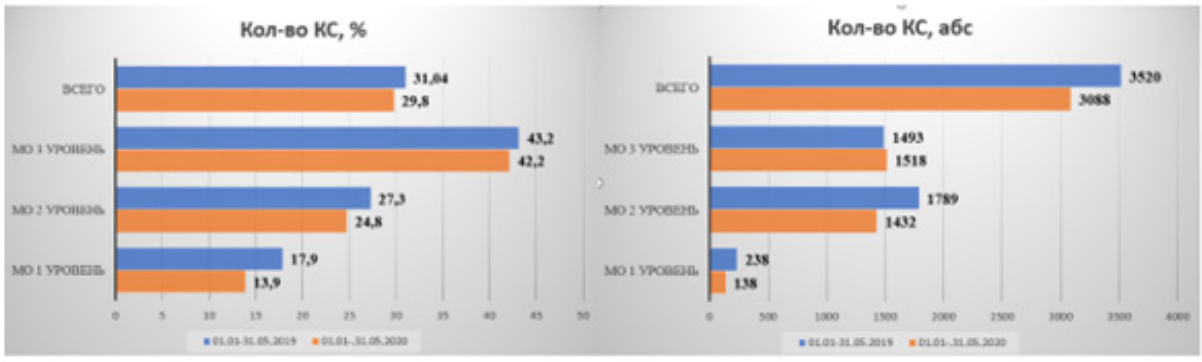

Figure 1: Number of cesarean sections.

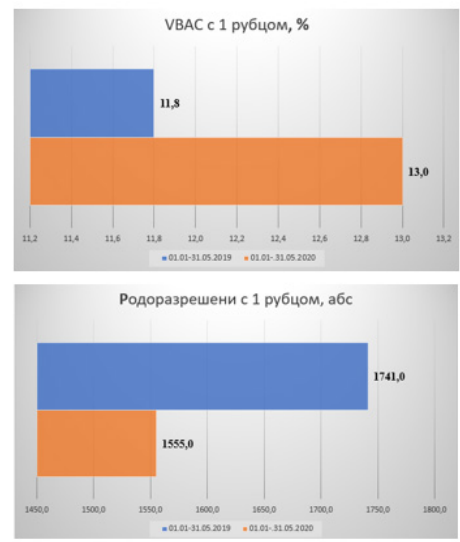

Figure 2: Delivery with a scar on the uterus through the vaginal birth canal. 


\begin{tabular}{|c|c|c|c|c|c|c|}
\hline & ем выораныным мо & & & & Сводка на аериод с с & 0 по 29.02.2020 \\
\hline 1. Nerp. & 2. Кол-во КС в группе & $\begin{array}{l}\text { 3. Количество женшин в } \\
\text { груше }\end{array}$ & 4. Размер группы (\%) & 5. Частота КС в групnе $(\%)^{6 .}$ & в общуюо частоту КС (\%) & $\begin{array}{c}\text { 7. Относительный вкал групшы } \\
\text { в общуюо частоту КС (\%) }\end{array}$ \\
\hline$\frac{1}{2}$ & 195 & & $20,6 \%$ & $17,87 \%$ & $3,68 \%$ & $11,19 \%$ \\
\hline & ${ }_{34}^{327}$ & 510 & $9,63 \%$ & $\begin{array}{l}64,12 \% \\
\quad 3617 \%\end{array}$ & $6,17 \%$ & $18,76 \%$ \\
\hline $2 \mathrm{a}$ & 293 & 416 & $7.85 \%$ & $70.43 \%$ & $5,53 \%$ & $\begin{array}{l}1,99 \% \\
168 . \%\end{array}$ \\
\hline 3 & 76 & 1853 & $34,98 \%$ & $4,1 \%$ & $1,43 \%$ & \\
\hline & 142 & 516 & $9,74 \%$ & $27,52 \%$ & $2,68 \%$ & $8,15 \%$ \\
\hline & 14 & 164 & $3,1 \%$ & $8,54 \%$ & $0,26 \%$ & $0,8 \%$ \\
\hline $4 \mathrm{~b}$ & 128 & 352 & $6,65 \%$ & $36,36 \%$ & $2,42 \%$ & $7,34 \%$ \\
\hline 5 & 585 & 655 & $12,37 \%$ & $89,31 \%$ & $11,04 \%$ & $33,56 \%$ \\
\hline 5.1 & $\begin{array}{l}416 \\
169\end{array}$ & 485 & $\begin{array}{l}9,16 \% \\
3,21 \%\end{array}$ & $\begin{array}{l}89,77 \% \\
9941 \%\end{array}$ & $7,85 \%$ & $\begin{array}{l}23,87 \% \\
97 \%\end{array}$ \\
\hline & $\begin{array}{r}169 \\
75\end{array}$ & $\begin{array}{r}170 \\
78\end{array}$ & $\begin{array}{l}3,2,4 \% \\
1,47 \%\end{array}$ & $99,41 \% \%$ & $1,42 \%$ & $\begin{array}{l}9,7 \% \% \\
4,3 \%\end{array}$ \\
\hline & 86 & 114 & $2,15 \%$ & $75,44 \%$ & $1,62 \%$ & $4,93 \%$ \\
\hline $\begin{array}{l}7 \mathrm{a} \\
7 \mathrm{~b} \\
\mathrm{a}\end{array}$ & ${ }_{56}^{30}$ & $\begin{array}{l}31 \\
83\end{array}$ & $0,59 \%$ & $67.47 \%$ & $0.57 \%$ & $1,72 \%$ \\
\hline & $\begin{array}{l}50 \\
60\end{array}$ & 104 & $1,96 \%$ & $\begin{array}{l}67,47 \% \\
57,69 \%\end{array}$ & $1,13 \%$ & $3,21 \%$ \\
\hline $8 \mathrm{a}$ & 54 & 96 & $1,81 \%$ & $56,25 \%$ & $1,02 \%$ & $3,1 \%$ \\
\hline & 6 & 8 & $0,15 \%$ & $75 \%$ & $0,11 \%$ & $0,34 \%$ \\
\hline & 22 & 26 & $0,49 \%$ & $84,62 \%$ & $0,42 \%$ & $1,26 \%$ \\
\hline $9 \mathrm{ab}$ & $\begin{array}{l}0 \\
16\end{array}$ & $20^{6}$ & & $\begin{array}{l}100 \% \\
80 \% 6\end{array}$ & & \\
\hline & 175 & 350 & $6.38 \%$ & $\begin{array}{r}80 \% \\
\mathbf{5 0 \%}\end{array}$ & $0,3 \%$ & $0.92 \%$ \\
\hline $10 \mathrm{a}$ & 55 & $\begin{array}{r}580 \\
58\end{array}$ & $6,09 \%$ & $\begin{array}{l}50 \% \\
94.83 \%\end{array}$ & $3,3 \%$ & $10,04 \%$ \\
\hline $10 \mathrm{~b}$ & 120 & 292 & $5,51 \%$ & $41,1 \%$ & $2,27 \%$ & $6,88 \%$ \\
\hline ВСЕГО & 1743 & 5297 & $100 \%$ & $32,91 \%$ & $32,91 \%$ & $100 \%$ \\
\hline
\end{tabular}

Figure 3: An example of automated Robson classification in tabular form.

\section{АНА.ІІЗ ЧАСТОТЫ АБДОМІНА.ТЬНОГО РОДОРАЗРЕІІЕ.НИЯ ПО К.АССИФНКАЦÜ M. S. ROBSON}

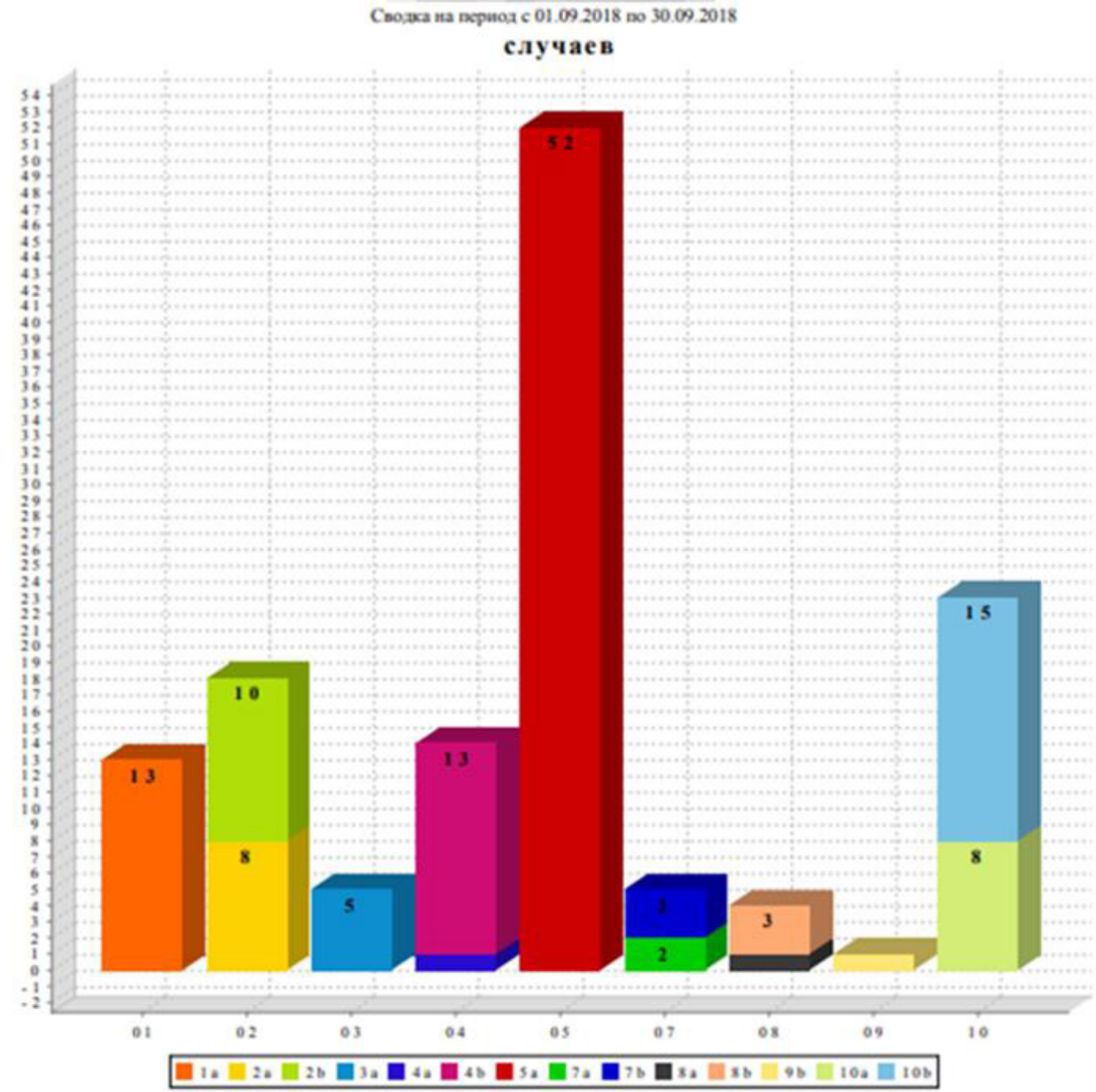

Figure 4: An example of automated Robson classification in graphical form. 


\section{Number of cesarean sections}

Decrease in the volume of deliveries by cesarean section both in absolute values and in $\%$ of the total number of deliveries (Figure 1).

Particular attention is drawn to a significant decrease in cesarean sections in level 1 and 2 medical facilities, which indicates a change in approaches to the formation of indications for surgery based on methodological work with the region on the automated Robson classification, as well as the correct and timely routing of patients due to information awareness of previous pregnancy outcomes.

\section{Delivery with a scar on the uterus through the vaginal birth canal}

With a general decrease in the number of deliveries in patients with 1 scar on the uterus, the proportion of VBAC increases from $11.8 \%$ to $13.0 \%$ (Figure 2).

These indicators indicate that doctors were able to see the protocols of previous operations, see and know how the operation took place (which incision in the uterus, how was suturing, etc.) and thereby plan and deliver patients with 1 scar on the uterus after the previous a cesarean section through the vaginal birth canal with minimal risks and is safe for the patient. That is, decisions on spontaneous childbirth in this category of patients are not made blindly, but with data on the previous pregnancy outcome.

\section{Conclusion}

The introduction of C-Register in the Sverdlovsk region has provided information in a standardized, unified and reproducible manner, which is essential for health care institutions wishing to optimize the use of caesarean section, as well as assess and improve the quality of care.

C-Register can help reduce the percentage of repeated cesarean sections by providing information about previous births online and allowing the doctor to quickly make the correct and safe decision on the management of pregnancy and childbirth.

\section{Project development prospects}

Implementation on the territory of other regions/countries and getting the possibility of interregional interaction, when a patient comes from another region/country and doctors receive data on previous pregnancies automatically based on digital detailed protocols of medical interventions.

Improvement of the Robson classification based on regional characteristics of the care system and levels of medical organizations.

Introduction of ratings of medical organizations on operative deliveries by caesarean section and development of motivational forms of medical management

Implementation of automated VBAC probability assessment individually for each pregnant woman with a uterine scar as an element of the medical decision support system. Thus, the electronic medical record will have a marker of the probability of independent birth, which will increase the safety of VBAC with corresponding benefits for women's reproductive health.

\section{Acknowledgement}

None.

\section{Conflict of Interest}

Authors declare no conflict of interest. 